\title{
New approaches within the history and theory of medicine and their relevance for homeopathy
}

\author{
Josef M Schmidt \\ Institute of Ethics, History, and Theory of Medicine, University of Munich, Germany
}

\begin{abstract}
Conventional sciences have brought forth a wealth of knowledge and benefits, but they have not always been clear and precise about their legitimate scope and methodological limitations. In contrast, new and critical approaches in modern sciences question and reflect their own presuppositions, dependencies, and constraints. Examples are quantum physics, theory and history of science, as well as theory and history of medicine, sociology, and economics. In this way, deprecative dogmatism and animosity amongst sciences ought to be lessened, while the field opens up for each science to redefine its appropriate place in society. This would appear to be a chance for homeopathy, as new approaches, especially within the social and economic sciences, suggest that being a follower of Samuel Hahnemann (1755-1843) may have advantages and privileges that conventional medicine seems to be lacking and whose relevance was overlooked during the rise of economic thinking in the last two centuries. Homeopathy (2014) 103, 153-159.
\end{abstract}

Keywords: History of medicine; Theory of medicine; Homeopathy; Samuel Hahnemann; Social sciences; History of Economics

\section{Introduction}

Basic research in medicine is commonly associated with laboratory, clinical, and epidemiological studies undertaken by highly specialised natural scientists. However, under the postmodern conditions of late capitalist societies, the assessment and development of medicine is no longer reserved to medical experts alone. Instead, a multitude of actors, from lawyers and politicians to economists and traders, are shaping the future of medicine. Accordingly, besides the natural sciences, the humanities are increasingly gaining relevance to observe and eventually supervise the many changes to which medicine is subjected at present. To be sure, within the social sciences basic research is also necessary and, in fact, under way. Against the background of relativism of values and crisis of author-

*Correspondence: Josef M Schmidt, Institute of Ethics, History, and Theory of Medicine, Ludwig Maximilian's University of Munich, Lessingstr. 2, 80336 Munich, Germany.

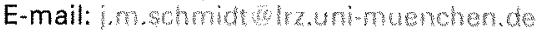

Revised version of a paper presented at the 66th Congress of the Liga Medicorum Homoeopathica Internationalis in New Delhi, India, on 3 December 2011.

Received 22 October 2012; revised 26 July 2013; accepted 27 August 2013 ity, today every science permanently has to question and reassure its own basis, scope, and destination. Generally, a high level of dynamics in any field may signify problems, but also good prospects - for those who know how to profit from them. In particular, within the currently changing scientific landscape, homeopathy is being challenged to find and redefine its appropriate place - potentially with the help of new approaches within the history and theory of medicine.

Since its founding by Samuel Hahnemann (1755-1843) some two hundred years ago, homeopathy has accomplished impressive achievements. Examples being the curing of countless diseases, individually as well as in epidemics, ${ }^{1}$ popularity among millions of patients all over the world, political successes, professionalisation and institutionalisation, ${ }^{2}$ and scientific research, from case studies and clinical trials to basic laboratory research. Nevertheless, recognition and full appreciation by conventional medicine is still lacking.

How can this paradox be explained, how can it be resolved? The thesis suggested in the following is that conventional medicine's rejection of homeopathy's claim of being a scientific medicine stems mainly from an inaccurate understanding of the scope, task, and limits of 
sciences, and their appropriate status in our lives. On the other hand, if we actually take all sciences as tools for cognition and practice, rather than as authorities forcing us to subdue ourselves under their implicit reductionist world-view, and if we apply their critical approach to themselves, to their specific methodology and limited horizon, up to the point that they reveal their own presuppositions and restricted validity, we may regain a fresh and uncaged look upon reality.

\section{Theory of medicine}

Starting with the most certain and least disputed fact among homeopaths: Homeopaths are practicing homeopathy, are they not? But what does this mean, what are they actually doing? Is a simple, general answer possible at all - or is any answer dependent on theory?

The usual assessment given by conventional medicine, the science closest to and yet most uncomprehending of homeopathy, reads approximately as such: Homeopaths are not using material medical substances, but ultramolecular dilutions. They do not prescribe according to conventional diagnoses based on objectifying technologies, but according to subjective complaints and idiosyncrasies. And instead of trying to remove material causes of diseases, they treat according to the principle of similars, which would not be considered scientific. Since clinical trials conforming with the gold standards of evidence based medicine, such as randomised double-blind studies, generally are said to not show a significant difference between homeopathic and placebo treatment, conventional medicine quickly concludes that homeopaths are practicing placebo therapy.

This statement, however, cannot be considered to be scientific - as long as it does not mention its own presuppositions and limiting framework. Correctly stated it should read: Under the premise of a naive materialism and the quantitative statistical method, neither homeopathy nor placebo therapy may adequately be assessed and understood, because they may possibly be phenomena escaping the conventional set of scientific categories.

A rebuke of ungrounded claims and pretensions by conventional medicine, however, should not be misunderstood as a rejection of the modern scientific method at large. The method of systematic observation, measurement, and experiment, and the formulation, testing, and modification of hypotheses, as it is successfully performed in physics, chemistry, as well as in conventional medicine, proves to be very efficient and nobody likes to abandon their achievements. "She simple, but crucial problem is that these positives become undermined by a dark and threatening side for humanity, when its instrumental function is forgotten and the whole world, including our lives, would be considered to be nothing more than what scientists are capable measuring and outlining on their tables.

In quantum physics, one of the most sophisticated and consistent branches of natural sciences, the scientific approach has long ago arrived at the point where the basic assumptions of conventional sciences, their simple realism, objectivism, and materialism, have proved to be untenable.
Instead of still hoping to find out whether "reality" essentially consists of particles or waves, scientists can show that the act of measurement, rather than detecting allegedly objective entities, leads to a collapse of the system as a whole and constitutes and fixes nothing but a man-made image of the world. If the scientist asks nature questions appertaining to particles, she provides him/her with particle data, if he/she asks questions regarding waves, her wave responses will induce him/her to create a wave-based view of the world, etc.

The same scientific insight, relativising conventional science and putting it in its proper place, can be found in modern biology, in the form of radical constructivism. Perception is here no longer deemed a passive reception of data coming to us through the senses from an allegedly objective world outside, but rather a reconstruction process run by the subject, depending on his/her disposition, interest, history, etc. Accordingly, dogmatic concepts, such as truth, reality, or objectivity, are replaced by the pragmatic criterion of viability, i.e. the test whether an idea or conception actually works in practice or not.",

Modern theory of science addresses these issues in a more general but equally uncompromising way. While positivism, critical rationalism, and general constraints of methodology have been effectively refuted, in mathematics the establishment of the incompleteness theorem demonstrated the inherent limitation of all axiomatic systems. "Within philosophical logic it could be shown that any science rests on presuppositions that cannot rationally be derived from itself. " Pioneered by the elaboration of "thought styles" and "thought collectives" underlying any so-called scientific fact, ${ }^{3}$ in epistemology today it is widely accepted that science is basically a social process, operating successfully within the scope of certain paradigms. These, however, have no absolute validity but can be and in fact have been revolutionarily changed from time to time, as may be shown by the history of science.

Theory of medicine, inspired by these insights, has emerged as a discipline on its own right and developed significantly during the second half of the twentieth century. Contrary to the conventional assessment of medicine as nothing but an applied natural science, it has now become accepted that medicine has to be considered a practical science sui generis - corresponding to the traditional concept of the art of healing. Since medicine is primarily constituted around the assignment of the physician to help the patient, i.e. around the doctor's duty to act or to give advice, acquisition of knowledge may never be a detached goal in itself, but has only a secondary status, as a means to facilitate the primary aim of beneficent action. ${ }^{15}$

Apart from the clarification of its current status, modern theory of medicine has also developed concrete models to broaden its approach to, and the comprehension of, its genuine object, the human being. To that end the suggestion has been made to introduce the concept of subjectivity, i.e. the human subject, into medicine. ${ }^{1 / 3}$ Along these new lines of thinking, the biopsychosocial model of the human being was expounded as a possibility to perceive and to treat the patient as a unity of physiological, mental, and 
social levels of existence, as well as a unity of a human subject and his/her individual environment. Contrary to the conventional reification of people as mechanistic physico-chemical automatisms, here life, illness, and healing of the patient are understood in terms of a process of meaning, functional and situational cycles, etc."

By means of this dynamic model of man, which today in the theory of medicine is considered to be one of the most sophisticated and consistent, ${ }^{\text {th }}$ the practice of homeopaths may be described and understood in a most suitable and illuminative way. Instead of taking material entities, such as human bodies, diseased organs, and medical substances, as a basis of thinking, the functional, cybernetic, and semiotic approach to the phenomena of the living, advocated here, can acknowledge patients as living beings constructing their world and actual state by their performance of attributing and processing meaning. For example, when the patient is in a state requiring a specific remedy, the physician detects this peculiar need by means of a semiotic interpretation of his/her symptoms and offers him/her that remedy - and the patient, by performing a functional cycle of processing the remedy's information, ultimately cures himself/herself. Therefore, it is not the remedy that is healing the patient, but the patient himself/herself (by means of the remedy), because he/she is the only living protagonist in this process. And it is not the disease or the symptoms that determine the right remedy, but the physician, because actions, such as finding and choosing a remedy, can only be accomplished by a living being,

The most striking difference of this sound and up-to-date model of man, in comparison to the conventional materialistic one, is that it may represent and explain what homeopaths are doing in a scientific way - without being handicapped by materialistic objections and scepticism. When processes of meaning are primary in the world of the living, it appears to be secondary whether medicinal information perceived and processed by the patient is physical, chemical, or virtual - as long as it exactly represents the meaning upon which the patient is fixated in his/her current state or process. In addition, the terms and concepts suggested by the biopsychosocial model might provide a valuable tool for homeopaths to scientifically clarify and specify their own understanding.

\section{History of medicine}

But how is it that this most advanced and scientific view of the human being is nothing like as well known and widespread in the medical community as the conventional, comparatively trivial, materialistic one? To answer this second paradox, the medical and natural sciences have to be put aside for a moment and the social and moral sciences, the humanities, considered as well.

From the perspective of sociology, humans are social beings, i.e. they associate and socialise, building up societies - in a specific way. While conventional sociology naively used to examine societies, as if they were neutral objects of research for independent scientific observers, new and critical approaches are stressing the mutual inter- dependences between individual subjects and society as a whole. Since a society is not an aggregation of material things, but the result of mental processes of meaning, performed both individually and collectively, its form and existence depend on its own reconstruction process by its subjects, who in turn are constituted by an incessant collective construction and upholding of meaning. ${ }^{\text {ta }}$

An example from communication science may make this point clearer. Exceeding conventional linguistic approaches with their analyses of words and phrases (as if they were objective entities), from an advanced critical perspective, language appears to be a social phenomenon. It needs intersubjectivity, i.e. dialogue partners, and cannot be created or developed by a solipsistic person on a lonely island. Even a hermit can only converse with himself/herself or his/her God, if he/she has before learned to speak in a social framework: with his/her mother, family, friends, or colleagues. We are actually born into our language. It is first and we, as its speakers, are second. That way, it constitutes us as native speakers of German (as in Hahnemann's case) or English, etc. Language is a process of meaning, whose actuality depends on the performance and participation of its speakers. On the other hand, to understand what language is, one cannot approach it from outside, from an allegedly neutral position, but has to participate."

Applied to homeopathy, these intermediate results from critical social sciences suggest the conclusion that, analogously, there may be no way to understand homeopathy without participation, i.e. without truly practicing it. Nevertheless, when language, science, and homeopathy are social processes of meaning, the question arises: What kind of meaning is being processed here, and in what mode and manner?

At first glance, economic science does not seem to have anything to do with this issue, but taking a deeper look, it turns out that economy has a tremendous impact on virtually every realm of our lives, from the way we view ourselves to the way we run our sciences.

Conventional economics, as it is commonly taught at universities and business schools, claims to explain economy in terms of scarcity of goods, practical constraints, and money as a means of barter - as if commodities, merchants, and markets have always existed. Egoistic selfinterest of people is not being questioned, but presupposed and thus sanctioned, while economic problems are examined and treated in a way an engineer would analyse and fix a machine running independently of himself/herself. To be sure, this seemingly objectivistic view is not objective but highly biased. It serves as a plea for the freedom of markets, as does the ideology first suggested by Adam Smith (1723-1790), the appeasing promise that a kind of "invisible hand" would transform the results of selfish economic players into the wealth and welfare of nations. Meanwhile, however, financial and economic crises all over the world have sufficiently shown that this is not the case. ${ }^{2.3}$

Trying to get to the bottom of the issue, it turns out that money is not a thing, a substance, or anything owning an intrinsic value, but a form of thinking, a mode by means of which people socialise in modern capitalist societies. 
Just as we always find ourselves in the midst of the language spoken in our country, we always find ourselves in the midst of a specific form of thinking in terms of money. As we cannot learn to speak without participating and accepting the language spoken in our infant environment (our mother tongue), we cannot learn to think and calculate without participating and accepting the logic of money as the origin of our basic logical categories.

Together with the insights of critical sociology, theory of science, constructivism, etc, this means, that our view of the world in which we live is mainly constituted by our thinking in terms of money. Since money is nothing more than an abstract form of thinking, it can actually transform everything it touches into a commodity. Contrary to living beings or physical goods, money is free of qualitative attributes, it is bare abstract quantity, yet can be augmented by smart trading or by means of interest. While natural resources are limited and cannot be infinitely proliferated, money can and indeed exerts the inherent temptation to do so. ${ }^{25}$

Hence, in capitalist civilisations the basic intention pervading all realms of life and culture, the utmost incentive, end, and merit is the turnover and multiplication of money, called economic growth. To that aim, almost everything and everybody is prone to be considered as a means for financial gain. Physicians, as well as pharmaceutical companies (if they like it or not), are tempted to use patients as a means to make money. Scientists (if they like it or not) tend to deliver results that meet the expectations of their sponsors. Needs for new products (healthy or not) are incessantly created by advertising - for the main purpose of acquiring new consumers. ${ }^{2}$ Significantly, the gross domestic product, as the grade of monetisation of life, is considered as an indicator of the standard of living. However, it is only a quantitative measurement, ignoring all the qualitative dimensions life may have.

The predominance of money, however, is not inevitable, as in the case of an anthropological constant or its like. The science of history may teach that it was not always the case, at least not to today's extraordinary extent. Misleadingly, in conventional historiography, greediness for money was usually imputed to all epochs likewise or ignored entirely. By means of a comparative approach, however, involving the history of economics, it becomes obvious how many profound and dramatic cultural and scientific changes had occurred in strict correlation with the rise of modern monetary thinking during the last centuries, up to the present.

Roughly speaking, during the Middle Ages in Europe, agriculture and subsistence economy prevailed, and money, in the form of gold or silver coins, played no prominent role. The majority of Europeans lived, worked, ate and drank and helped each other mainly on the basis of Christian conventions and morals - without interposing money or financial calculation upon their actions. The sick and invalid were cared for in their families or in hospices of fraternities, and healers, if available, were paid in kind. As soon as the first stock markets were founded and bank notes printed, however, a hitherto unknown inquietude, agitation, and dynamic emerged, aroused by the historically new incentive to proliferate money by means of bold trades and investments. This resulted in the discovery and conquest of new continents, colonisation and slavery, as well as exploitation and contamination of nature. ${ }^{27}$

It was in the wake of these fundamental changes of living, striving, and judging, triggered by the new status of money as the predominant form of thinking, that the modern natural sciences emerged - by means of an explicit emancipation from traditional teleological thinking. Since Francis Bacon (1561-1626), the basic attitude of modern scientists towards nature is no longer respect and the wish to live in harmony with her, but the temptation to prise out her secrets (with screws and clamps) and control her - because money can be made with inventions based on knowledge gained in that fashion. Quantification, mathematisation, standardisation, reproducibility, materialism, positivism, reductionism, etc., i.e. concepts on which conventional modern science, and, from the nineteenth century, conventional modern medicine are essentially founded, would not make sense without the context of the socialisation process in terms of money in modern capitalist societies. Obviously, to indigenous cultures, these concepts must have seemed absurd.

Another side effect of the dominance of money, as a form of thinking, was the acceleration and concentration of all activities in life. This may be shown in cultural studies, provided they are done critically. After the medieval ban on usury was eroded and finally abandoned, as a factor for earning (or loosing) money by means of interest, the significance of time rose tremendously in public awareness. Eventually, time was actually equated with money. Clocks and watches became omnipresent, physiological time was replaced by chronometry, and clockworks became the paradigm for any kind of scientific mechanism. Besides space, time can also be, and in fact has been, exploited by charging it with ever new opportunities to make money. In Western civilisations, where consumers are saturated with durable material goods, such as refrigerators, cars, or TVs, the markets increasingly prompt people to consume ever more in ever less time. For example, clients are tricked into conditions where they find themselves simultaneously talking on the phone, using their computer, listening to music, reading a newspaper, having a coffee, going by train, etc. This kind of time compression, known under the euphemism "multitasking", is a direct outcome of the dominance of money in capitalist civilisations. Meanwhile, its undesirable effects have also reached medical schools and medical offices. Everywhere the treadmill keeps accelerating. ${ }^{2}$

Not even the science of philosophy, i.e. the selfreflection of the mind, seems to be free from the impact of money as a form of thinking. Transcending conventional philosophy as a mere history of philosophers, a critical radicalised approach may discover that the term "ratio" derives from the financial accounting of the merchants of the Roman Empire. With this insight, however, the concept of rationalism, and its derivates, such as enlightenment, progress, emancipation, etc., may appear in a new light. To speak of progress, for example, one has to know, where to go or, at least, what is worthwhile. In societies 
dominated by money as the prevailing form of thinking, the definition of their utmost reference point would be: Good is what results in economic growth. Other dimensions of life would probably be missed. Since the nineteenth century, philosophers have been increasingly taken in by concepts of dynamics, progression, enhancement, etc., without realising their own status as a mouthpiece of the spirit of the age rather than original creators of a new philosophy.

Also the modern concept of autonomy may eventually turn out to be a delusion by the "modern subject", which was last constituted when René Descartes (1596-1650) coined the formula "ego cogito, ergo sum" (I think, hence, I am). At a time, when people started to pin their hopes on money rather than on personal relationships with fellow human beings, due to the first stock market crashes, the faith in the abstract value of money was always mixed with fear of loss. This existential doubt, pervading modern times in an ever increasing manner, was Descartes's starting point. His conclusion, however, the alleged certainty of his subjectivity, may rather look like self-deception, as his imaginary autonomous ego was still dependent on social processes, such as speaking, thinking, and calculating in terms of money. In fact, the concept of an abstract subject thrown back on itself proves to be the result of a generalised process of thinking in terms of money and its inherent uncertainty.

Even the science of ethics looks like being infiltrated by rationality in terms of monetary, quantifying, and competitive thinking. From the eighteenth century, for example, in utilitarianism, it has been argued that an action would be ethical when it maximises the overall benefit of the greatest number of individuals. From the nineteenth century, in Social Darwinism the fact of struggle for existence, as observable at capitalist markets, may at first have been attributed to the animal kingdom, to finally deduce it from there - in order to justify unsocial policies. According to modern medical ethics, in a patient's critical situation the interests of all players (economic, financial, social, familial interests) are to be negotiated - according to the paradigm of bargaining at the marketplace. Guiding ethical principles are admitted only on a medium level, such as beneficence, nonmaleficence, respect for autonomy, and justice. ${ }^{n 1}$ In such a framework, however, human dimensions, such as love, faith, duty, guilt, shame, virtues, etc. may only be perceived as factors among others and thus misunderstood and devalued.

Finally, also in theology, a reflection of this global development may be detected. The traditional Christian conceptualisation of God as an eternal, unchangeable substance or essence may have been perfectly plausible (up to the Middle Ages) - as long as life on earth conformed and corresponded to it. After economic falls of grace, such as the selling of indulgences, and an increasing rationalisation of religion, in the wake of industrialisation and the acceleration of life, contemplation was lost and competing individual interests required a new civic moral. This included strategies to survive on merciless markets, such as canting and pretending. The concept of truth, and with it its warrantor, God, were thus challenged and ultimately abandoned. Friedrich Nietzsche (1844-1900), the seismograph of bourgeois dishonesty and prophet of the dawning nihilism in the nineteenth century, cried out the gruesome diagnosis: "God is dead... and we have killed him!".

To bring all these insights from different theoretical sciences together to a uniform conclusion, it might be stated that in the modern age, especially during the last 200 years, in capitalist civilisations the process of socialisation in terms of money has transformed all realms and dimensions of life, including the sciences, tremendously. This has happened in a way that today, from the perspective of conventional natural science, only material things and quantitative, exploitable relations seem to be accepted as real while everything else is likely to be neglected, for example qualities, values, or processes of meaning, which are intangible for these categories. This is the reason why within conventional medicine the biopsychosocial model of humans has no chance to play a significant role and why homeopathy is still being assessed from a materialistic, mechanistic, and quantifying background only, by means of statistics and measurements.

\section{Homeopathy}

Having realised this, as a third paradox the question arises: How is it possible to both recognise and free oneself of this all-embracing dominance of thinking in terms of money - if this really has infiltrated, and gained control over, everybody's mind and logic.

At this point, today's homeopaths are being challenged to ask themselves the question: "What does practicing homeopathy mean for me?" As a matter of fact, it is from this same issue that most essential questions may arise, such as: "What am I doing?", and: "Who am I?".

Here the history of homeopathy may provide the crucial key. To be sure, any investigation about the essence of homeopathy has to consider its founder, Samuel Hahnemann, and his unique method of healing. By contrast, conventional modern medicine's conception of itself is rather ahistorical. In fact, it has been constituted during the last two centuries by a variety of socio-economic conditions, incentives, and interests, and can be practiced without knowing any of its many historic protagonists by name or character. In comparison, homeopaths practice a system of medicine which was not compiled by teams of anonymous scientists, but founded by a well-known single man, who moreover lived an exemplary moral life, virtually free from conflicts of interests, or the like. ${ }^{34}$ This difference can hardly be overestimated.

In antiquity, awareness of the distinction between an idea and its concrete incarnation was still present. Aristotle's answer to the question "What is virtuous?" was: "What a virtuous man is doing!", thus referring to the actual practice of a concrete human being, instead of risking being misled by language, logic, and other fallacies when trying to give an abstract definition. In homeopathy, homeopaths do have a human paradigm with an exemplary character who lived at a time before the tremendous impact of rationalisation in terms of money had infiltrated all Western societies, cultures, and sciences, especially 
modern medicine. Thus, homeopaths may take Hahnemann as a beacon in this respect, lighting their way in turbulent times and guarding them against erroneous trends while conventional medicine lacks a comparable corrective against its liability in principle to being dominated by economics. While at present nearly everybody is socialised from infancy to a way of thinking whose function is to ensure the expansion of money markets rather than to find anything like truth, Hahnemann was exactly and uncompromisingly striving towards the latter, for the benefit of his "human brethren".

Of course, Hahnemann was no saint. As a man born at the interface of two unequal epochs, he was torn between a conservative metaphysical belief in God, truth, morality, providence, unprejudiced observation, etc., on the one hand and progressive scientific ambitions to found a rational method of therapeutics, with a vision of healing diseases with mathematical certainty, on the other. After initial rationalistic exuberances, however, in 1819 he came to a well-balanced concept, the homeopathic art of healing. ${ }^{3}$

At the same time he noticed that a rising proportion of the population were no longer healthy, but in a state of chronic disease. In 1828 he interpreted these observations as infections with a "chronic miasm": psora, sycosis, or syphilis. On the threshold of the bacteriologic era, concluding by analogy from his clinical observations, Hahnemann suggested a theory according to which chronic diseases would be caused by transmission of invisible morbific agents which he called "miasms" (although this term was traditionally used meaning maculation from evaporations from the earth) from human to human. According to Hahnemann, the bulk of non-venereal chronic diseases would be caused by "psora", an internal scabies disease, while sexually transmitted diseases would have two possible origins, "syphilis" or "sycosis", the latter being a disease entity described by himself as a combination of gonorrhoea and acuminate condylomata. Interestingly, this was at a time when the unhealthy effects of industrialisation, monetising, acceleration, etc. were starting to be felt in Saxony (Leipzig, Köthen) as well as by Hahnemann's corresponding patients in other countries.

Certainly, the scientific notions and concepts of which Hahnemann could avail himself in his day were limited. But obviously he tried his best to apply them with the aim to advance medical science. In fact, he always considered his life's work as "service at the altar of truth". "To be sure, without Hahnemann's noble-minded attitude and his high estimation of humanity, homeopathy would not have been founded. Hence, homeopaths have a direct human paradigm to follow in terms of righteousness, trustworthiness, and uncompromising quest for truth. When today's conventional medical doctors are advised by non-medical officials, such as laboratory engineers, pharmacists, attorneys, economists, politicians, etc., on what to do and what to prescribe, their decisions often appear to be remote-controlled by monetary interests. As a counterweight, homeopaths can still learn from Hahnemann about how it was and how it would be when a doctor dares to think and act on his/her own account, just vouching with his/her conscience and faith - while thus largely immunising himself/herself to modern forms of thinking in terms of money and monetising.

Hahnemann was definitely conversant with monetary matters. After having suffered from its shortage as a young physician and head of a growing family, in his later years he introduced an innovative system for invoicing his patients in advance. Thus, when he left his home in Köthen for Paris in 1835 , he was able to bequeath to his daughters two houses and a considerable amount of money. "What is decisive, however, is that his dealings with money were constricted to a considerate use of it, in the sense of the Aristotelian conception of "oikonomia" - without affecting his world-view or general thinking in principle. He never saw money as a means of augmenting money (as a goal in itself), in the sense of Aristotle's counter-concept "chremastike", the self-referential art of money-making." Remarkably, Hahnemann's doctrine is still untinged from thinking in the form of money, i.e. free from concepts of quantification, standardisation, mathematisation, reproducibility, materialism, mechanism, statistics, etc. On the contrary, his approach is qualitative, individualising, hermeneutic, teleologic, and full of respect for patients' idiosyncrasies and phenomenological details. Homeopaths would be well advised to consider this legacy as a privilege.

The homeopathic method itself may in the end provide a powerful corrective tool for all those whose minds are infiltrated and dominated by money as a form of thinking. Insofar as by the principle of similars true healings can be accomplished, homeopaths should be well-disposed to avail themselves of this method - to heal themselves from miasms of any kind, including mental ones. Indeed, in the history of homeopathy Hahnemann's concept of "miasm" proved broad and pliable enough to be interpreted not only as a physical infection, but also as a disposition, diathesis, simple substance, original sin, mental structure, etc.

Eventually, the critical scientific approach presented so far, may prove to be homeopathic in a figurative sense, resembling the Buddhist or Hindu approach of reducing illusions rather than the causal-analytic affirmative one of conventional modern medicine. It rests on the assumption that late-borne children of a late capitalist era cannot help but start thinking with bewildered minds anyway just in analogy to psoric patients whose life-force according to the homeopathic doctrine is said to be deranged. If, however, according to Hahnemann, the deranged lifeforce is provided with a slightly enlarged image of its enemy, i.e. the image of the miasm in the form of a potentised remedy, vitality will thus be prompted to raise its energy and defeat this miasm. After having been dominated, the life-force will restore itself and regain its sovereignty. ${ }^{4}$

Analogously, modern subjects of heteronomy would have to detect their predominating mental miasm, their own domination by thinking in the form of money. They would have to recognise and face this in a condensed form, i.e. brought to the point, and in an uncompromising way, in order to become aware and able to rid themselves of it. With this clearing of his/her mind, the homeopath may finally be capable of also freeing homeopathy from 
unrelated economic interests and capitalist schemes, such as the permanent pressure to be innovative, competitive, and profitable. They may realise on a conscious and scientific level that, contrary to conventional modern medicine, homeopathy could also be perfectly practiced in subsistence economies, without turning over ever increasing amounts of money on incessantly expanding markets.

\section{Conclusion}

In conclusion, being true to Hahnemann may have even more challenging consequences than just prescribing homeopathic remedies. First of all, his righteous and strong character may inspire his followers to dare to think freely and independently (aude sapere). Secondly, a comprehensive interpretation of his principle of similars may lead them to an extensive study - by means of all modern sciences - of the conditions which are limiting and distorting their own free and genuine thinking and acting. And thirdly, if they finally recognise the kind of mental miasm described above and rid themselves of it, they may free themselves as well as homeopathy, whose core has been unsettled by continually rising monetary influences. As a coherent side-effect, the true Hahnemannian will thus embark on a path leading to the ultimate challenge of life, which in ancient Greek philosophy was called "gnothi seauton" (know yourself) - corresponding to what in the Vedantic Upanishads was considered to be the utmost wisdom: to realise "tat twam asi" (that is you).

\section{References}

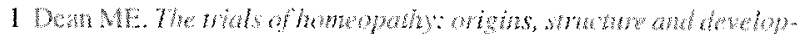

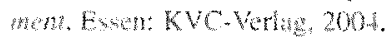

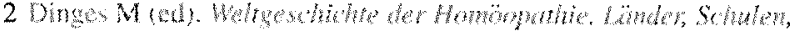

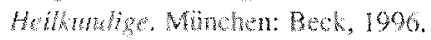

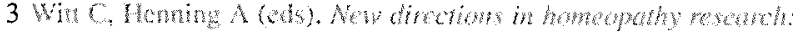

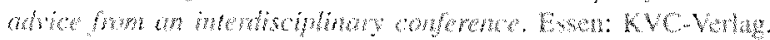
Why

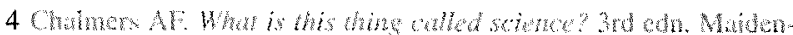
hwat: Opon Univerity Pros, 1909

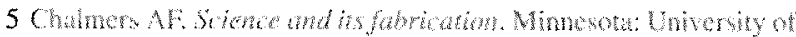

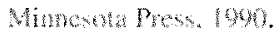

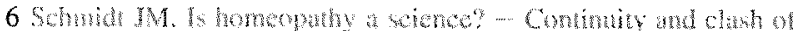

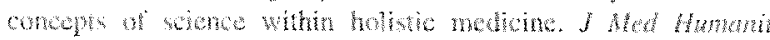

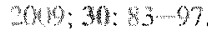

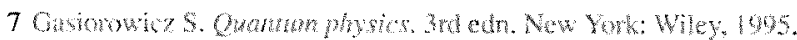

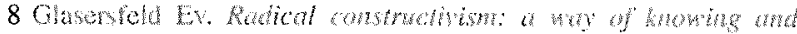

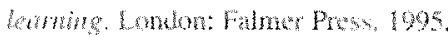

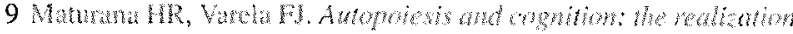
of the thing. Dorbeche Reidel, 1080 .

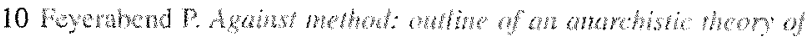

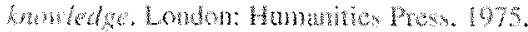

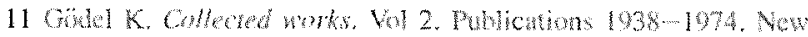

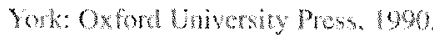

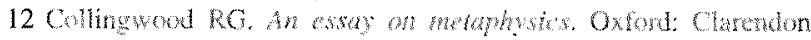
Pratas, Bous.

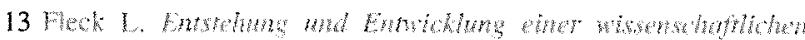

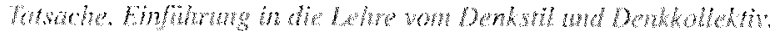
Bast: Sonwhe 1935

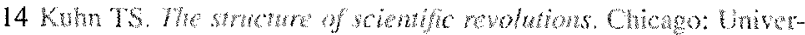
sity of chinge prosin. 1962.

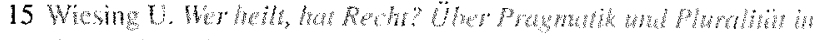

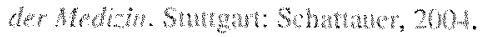

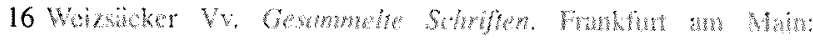
Sublown, $386-200$.

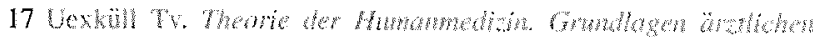

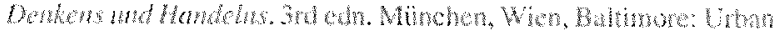

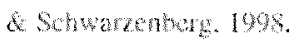

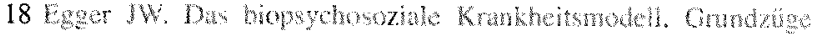

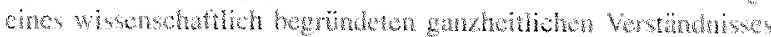

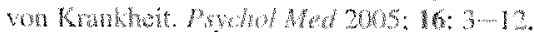

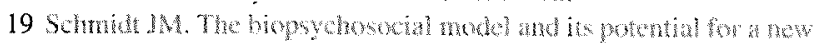

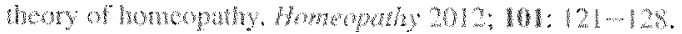

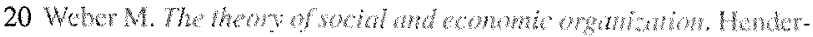

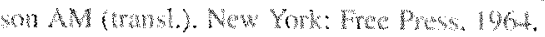

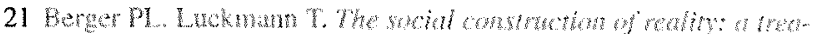

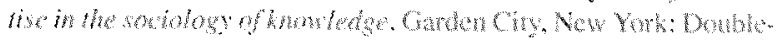
$32 y .1066$.

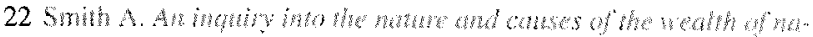

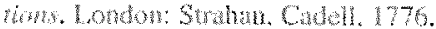

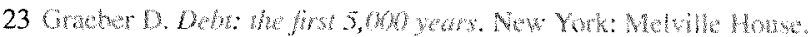
2011

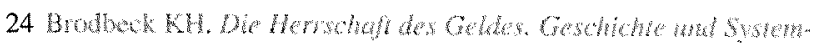

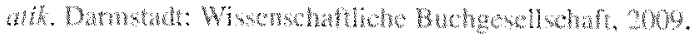

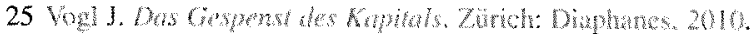

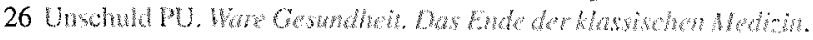
Munchen: ber, $200 \%$.

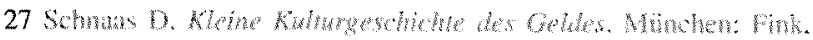
2010

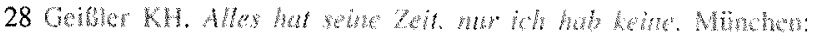

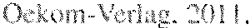

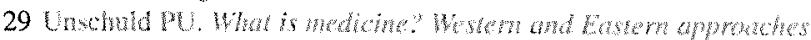

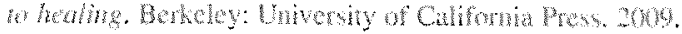

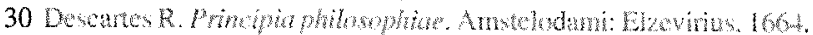

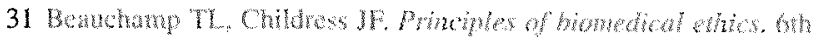

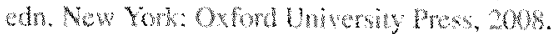

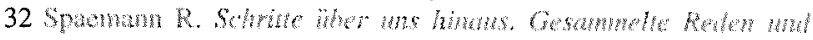

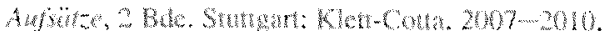

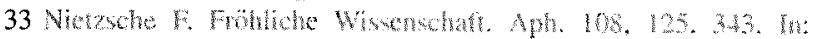

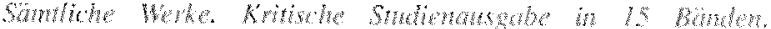
Whenen: DTV. 1980 .

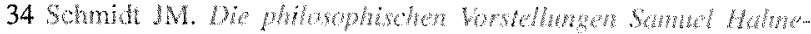

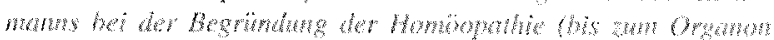

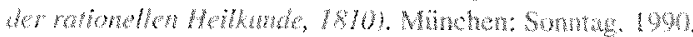

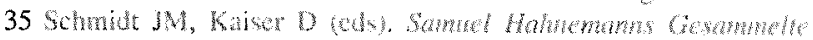

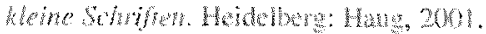

36 Bartlett RC, Collins SD (transl.). Aristotle's Nicomachean ethics. Chicago: University of Chicago Press, 2011.

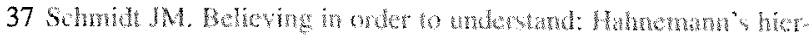

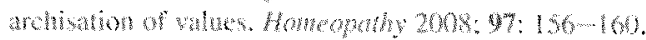

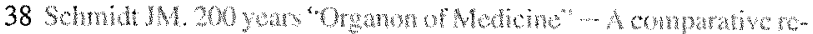

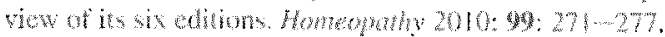

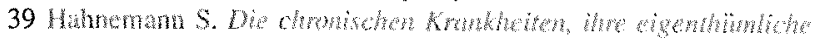

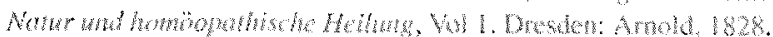

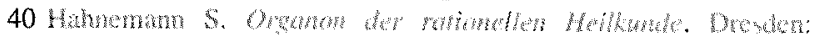
Anoth. 10 , pit.

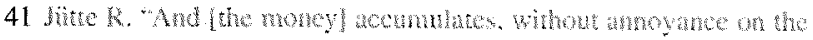

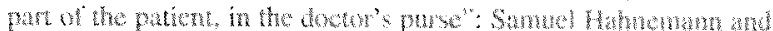

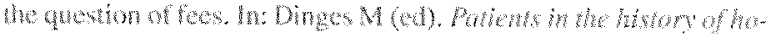

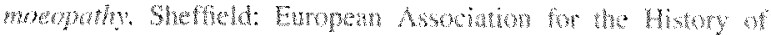

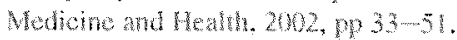

42 Barker $\mathrm{E}$ (transl.). The politics of Aristotle. Oxford: Oxford University Press, 1995.

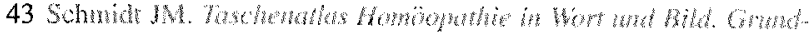

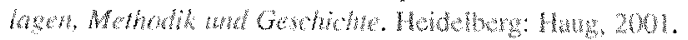

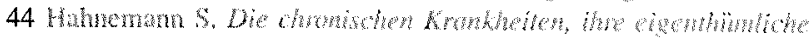

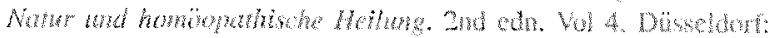

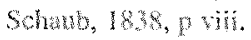

